Monatsschrift f. Geburtshülfe u. Gynäkologie 1917;46:185

\title{
Johannes Veit
}

Von A. Martin

Zum Gedächtnis!

Nur wenige haben dem so früh Dahingegangenen in seinem wissenschaftlichen Werdegang so nahe gestanden als wie der Schreiber dieser Zeilen. Zu E. Martins Zeiten pflegten die Assistenten der Frauenklinik bei der Berufung des im 3 jährigen Turnus einrückenden Mitarbeiters befragt zu werden. Damals äußerten Löhlein und ich, auch der schon verstorbene Benicke uns übereinstimmenci zugunsten des durch seinen Eifer und seinen wissenschaftlichen Ernst, aber auch durch seine per-sönliche Tüchtigkeit hervortretenden Joh. Veit: wir begrüßten ihn vertrauensvoll im Herbst 1875 in unserer Mitte! Hatte Löhlein ihn in seinen Kursen unterrichtet, so war mir die Leitung seiner ersten prak-tischen Betätigung als Geburtshelfer zugefallen: ich assistierte ihm bei seiner ersten Zangenentbindung und seiner ersten Beckenendlagen-extraktion. In dem so eigenartig traulichen Zusammenleben während eines gemeinsamen Assistentenjahres, während dessen E. Martin starb, K. Schroder seinen Platz einnahm, sind wir uns menschlich nahe getreten. Mit besonderer Teilnahme begleitete ich seinen raschen Aufstieg. Wenn auch unsere Lebenswege dann sich trennten, in der Universitäts-Erauenklinik und in der G3burtshülflichen Gesellschaft hat uns die Lebensarbeit vereint gehalten. In regem wissenschaftlichen Wett-kampfe blieben wir gleichstrebende Mitarbeiter, die sich anregten und förderten. Tief habe ich stets die außerordentliche Geistesfrische, den reich fließenden Quell seiner geistigen Arbeit bewundert, seine stupente Belesenheit, seinen unermüdlichen Fleiß und seine $\Lambda 5 / 8$ lseitigkeit. Das gab seinem persönlichen Umgang, aber auch seiner Teilnahme an unseren Diskussionen jederzeit einen besonderen Reiz. Ihm war besonders eigen die Neigung, die divergenten Anschauungen vermittelnd auf das den Wider par tnern Gemeinsame zu einen und der Aussprache einen versöhnenden Abschluß zu geben.

Sein Heimgang läßt eine klaffende Lücke in unseren Reihen ent-stehen: er War einer unserer Führer! Gerade jetzt, wo sich unter andtrem auf dem Gebiet unserer Therapie so durchgreifende Ent-wicklungsstufen herausbilden, wo so große Aufgaben auch auf alien Forschungsgebieten zur Lösung drängen, wird seine Mitarbeit, sein Scharfsinn, seine reiche Erfahrung schmerzlich vermißt bleiben.

Joh. Veit ruht aus $\lambda$ ron einem arbeits- und erfolgreichen Leben!

Die Fülle seiner Anregungen uncl Ideen wird auch Weiterhin die Entwicklung der Frauenheilkunde befruchten und für Generationen sein Angedenken lebendig erhalten. Wir aber, seine Altersgenossen und Mitarbeiter, werden mit seinen Schülern und seinen dankbaren Pflegebefohlenen auch seiner Persönlichkeit ein freundschaftliches Andenken beWahren! A. Martin. 